\title{
Factors Associated With Late Presentation to HIV Care Among Patients Attending in Public Hospitals of Mekelle City, Tigray, Ethiopia, 2018/19. Case- Control Study.
}

Teklay Araya Tesfay ( $\nabla$ teklayaraya19@gmail.com )

Mekelle University College of Health Sciences

Desta Hailu Aregawi

Hiwotea Melese Geltu

Kiros Belay Gebrekidan

\section{Research}

Keywords: Associated factors, HIV/AIDS, Late presentation, public hospital

Posted Date: January 9th, 2020

DOI: https://doi.org/10.21203/rs.2.20432/v1

License: (c) (i) This work is licensed under a Creative Commons Attribution 4.0 International License. Read Full License 


\section{Abstract}

Background The European Late Presenter Consensus Working Group, defines "late presentation" as initial presentation to HIV care with a CD4 cell count of $<200$ cells/ $\mu$ l. Globally, 36.9 million people were living with HIV, African region remains most severely affected, with nearly 1 in every 25 adults. In 2017, around 940,000 people died from AIDS-related illnesses worldwide.

Methods Hospital based case control study was conducted from Nov 2018-June 2019 in public hospitals of Mekelle city. Using simple random sampling technique 114 cases and 229 controls were included in the study. Data was coded and entered to Statistical Package for Social Science version 23 for data analysis. Variables with $p$-value $<0.25$ in bivariate logistic regression were selected for multivariable logistic regression to identify factors of HIV presentation. Odds ratio was estimated with $95 \% \mathrm{Cl}$ to show strength of association and p-value $<0.005$ was used to declare stastical significance in multivariable analysis. Results was summarized and presented by tables, and charts. Percentage, frequency, standard deviation and mean was calculated.

Result The mean age among cases, controls was 39.7(sd + 11.5), 34 (SD+10.2) respectively. Prior HIV related teaching before enrolment to care $3.48(\mathrm{AOR}=3.48(1.57-7.70)$, having symptoms while starting care 3.85(AOR=3.85(1.91-774), presence of chronic illness 4.59(AOR=4.59, 95\% Cl: 2.17-9.74) and Being challenged during care $1.84(\mathrm{AOR}=1.84,95 \% \mathrm{Cl}: 0.13-0.77)$ were independent predictors of late presentation to HIV care and support.

Conclusion and recommendation Prior HIV related teaching before enrolment to care, symptom while starting care, presence of chronic illness and challenge faced during care were significantly associated with late presentation. It is better to give emphasis in providing prior HIV related teaching and cousling.

\section{Background}

Human Immunodeficiency Virus (HIV) is described as lentivirus that causes acquired immunodeficiency syndrome, a condition in humans in which the immune system fails to contain life-threatening infection, which would otherwise be dealt with in non-infected individuals. With more than 1.5 million people living with HIV/AIDS (PLHIV), Ethiopia is one of the countries seriously affected by the epidemic(1). Globally, 36.9 million people living with HIV in 201721.7 million people were receiving antiretroviral treatment by the end 2017(2). Scale-up of antiretroviral therapy is on a Fast-Track trajectory that has surpassed expectations. Global coverage of antiretroviral therapy reached $46 \%[43-50 \%]$ at the end of $2015(3)$.

Human immunodeficiency virus (HIV) infection rests the leading cause of morbidity and mortality throughout the world. Since the start of the epidemic, around 76.1 million people have become infected and 35.0 million people have died from AIDS (acquired immunodeficiency syndrome) related illnesses. Globally, in 2016 there were 36.7 million people living with HIV, 1.8 million new HIV infections, and 1 million AIDS related deaths (4). Clients presenting late for care have been found to have less favorable outcomes than those who initiate early presentation and subsequently early initiation is associated with 
clinical and HIV improvement benefits, improving survival and reducing the incidence of HIV infection at the community leve (5).

In sub-Saharan Africa, only an estimated $59 \%$ of those testing positive for HIV are linked to care. An estimated $30 \%$ to $40 \%$ of patients initiating HIV care in sub-Saharan Africa are late presenters. Late presentation to HIV care is associated with significantly higher health care- related costs compared with early presentation.(6).As one of the sub-Saharan country the case in Ethiopia is not different, in 2016, there were 720,000 people living with HIV and 27,104 newly diagnosed cases. But only $67 \%$ of expected PLWH know their status and $59 \%$ of them were enrolled in highly active antiretroviral therapy (HAART) program, while significant proportion people living with HIV were died (7).

\section{Main Text}

\section{Study area and period}

The study was conducted in four selected public Hospitals of Mekelle city.

The study was conducted from March 18 to May 20/2019.

\section{Study design}

Institutional based unmatched case - control study was employed.

\section{Source population}

All HIV positive patients who enrolled to care in selected public hospitals of Mekelle city.

\section{Study population}

Cases: HIV positive individuals ( $\geq 18$ years) with a baseline CD 4 count of $<200 / u L$ or who had WHO clinical stage 3 or 4 at the time of first presentation (8).

Controls: HIV positive individuals ( $\geq 18$ years) who had a baseline CD4 count of $>200 / \mathrm{uL}$ or WHO clinical stage 1 or 2 at the time of first presentation.(8).

Inclusion and exclusion criteria

\section{Inclusion criteria}

All HIV positive patients whose age is greater than 18 and who have follow up during data collection period.

\section{Exclusion criteria}


Those who are newly diagnosed and unconscious patients was excluded.

\section{Sample size determination and sampling technique}

The sample size was calculated using open Epi-Info Version 7.2.2.2 statistical software by considering the assumptions for case control study. The sample was 104 cases and 208 controls. Accordingly, by adding $10 \%$ for the nonresponse rate the ultimate sample size was 114 cases and 229 controls a total of 343 .

\section{Sampling technique and Sampling procedure}

First, the sample size was allocated proportionally to the four ART treatment centers of Mekelle public hospitals according to the number of patients registered to take the treatment and simple random sampling technique was used to select the ART cases and controls.

\section{Study variables}

\section{Dependent variable}

Presentation to HIV care

\section{Independent variables}

Socio-demographic factors: Age, sex, educational status , place of residence, marital Status, employment status, monthly income of participants, owner of the house, transport fees, time taken to health facility they served.

Sociocultural factors: HIV disclosure status, history of alcohol consumption, Contact with commercial sex workers.

Heath system and provider factors : Challenge faced during care, prior HIV related teaching and information, treatment seeking anywhere before starting care.

Perceived Susceptibility and Perceived benefits: Perception of ART side effects, HIV as stigmatizing disease, stigma as barrier to HIV testing and starting care, benefit of early care.

Clinical factors: Time gap between testing and HIVcare enrollment, symptom during, presence of chronic illness. starting care, reason for HIV testing, feeling of ill while starting care, information about HIV before starting care, counseling, support of health providers, recommendation of patients to other patients, member of support group ,overall quality service.

\section{Operational Definitions}

Time to present for HIV care: Presentation of the participants to HIV/AIDS care dichotomized as early and late. 
Early presentation for HIV/AIDS care -:when HIV positive individuals (age 15 years and above) came with WHO stage I or II and a CD4 lymphocyte count of 200 cells/ $\mu$ l or more at the time of first presentation to the ART clinics of the institution.

Late presentation from an immunological point of view is enrollment into HIV/AIDS care with a CD4 count of $<200$ cells/uL (9).

Enrollment into care is being entered into the Pre-ART register at a health facility and assigned an OI/ART number (9).

Clinically, late presentation is defined as enrolment into care with an AIDS defining illness as prescribed by the World Health Organization and is classified as Stage 3 and 4 (6).

\section{Data collection tool and technique}

Four data collectors (BSc nurses) and two supervisors $(\mathrm{MScN})$ were selected and two days training was given them about the objectives of the study and how to approach the study participants. Then the data collectors were interviewed eligible and voluntary patients in a favorable place using structured questionnaire and the supervisors were supervised during the data collection process. The initial. English version of the questionnaire was translated to the local language Tigrigna and also translated back to English

\section{Data quality control}

Prior to data collection a two day training was be given by the principal investigator. Pre-test was conducted using $10 \%$ of the sample on HIV patients before two weeks to assess instrument simplicity, flow and consistency. The cleaning process was done by running simple frequency and cross tabulation after data entry for its consistency.

\section{Data processing and analysis}

The collected data was edited, checked visually for its completeness and the response was coded and entered in into the computer using SPSS version23 for entering and analyzing purpose. Descriptive statistics was computed and the result was summarized and presented by texts, tables, and grap.

Percentage, frequency, standared deviation and mean were calculated. First, binary logistic regression was used to assess the association between each independent variables and the dependent variable. Variables with $p$-value $<0.25$ significance level in bivariate logistic regression were transferred to multivariable logistic regression to assess the association between independent variables with the dependent variable. $P$-value $<0.05$ was used to declare stastical significance.

\section{Result}




\section{Socio- demographic characteristics of participants}

Charts of three hundred forty three participants (114 cases and 229 controls) were reviewed making a response rate of $100 \%$. The mean age among cases, controls cases was $39.7(s d+11.5)$ and $34(s d+10.2)$ respectively .Forty five (39.8\%)cases was in the age group of $41-49$ and controls $126(70.4 \%)$ was in the age group of $18-40$. Sixty nine (34.5\%) case and 131 (65.5\%) controls were females. Eighty four (35.0\%) cases and controls $156(65.0 \%)$ were living in urban.

Forty eight (36.9\%) cases and 2(63.1\%) controls attended primary school. Majority of participants 45 (36.9\%) were divorced among cases and 77(63.1) among controls. Regarding the occupation of the participants among cases, government employed and unemployed were 77(32.8\%) and 24 (31.6\%) respectively.

Out of the total cases, controls, 39(29.8), 92(70.2), were traveling more than 40 minutes to the health facility they served respectively.

\section{Socio-cultural factors}

Regarding alcohol consumption among cases, many times and sometimes drinkers were, 53(86.9) 36 (26.9) respectively. In this study, 84(35.3\%) case and 154 (64.7\%)) were disclosing their status to their partners . Thirty two (39.0\%) cases were having history of contact with commercial with sex workers.

\section{Heath system and provider factors of participants}

Among case, participants having difficulty of drug and shortage of materials were 13(34.2\%) $18(20.0)$ respectively. Seventy five (39.5\%), 39(25.5\%) case were didn't get prior HIV related teaching before care and got prior HIV related teaching before care.

\section{Perceived Susceptibility and Perceived benefits factors of respondents}

Regarding perception HIV as stigmatizing disease, 94 (32.8\%), 20 (35.7\%) cases were having perception of HIV as stigmatizing diseases and not having perception of HIV as stigmatizing disease. Thirty five $(30.7 \%)$ cases were perceiving as ART has side effect.

\section{Clinical factors of respondents}

In this study, 53(59.6\%), 61 (24.0\%) cases were having chronic illness and didn't have history of chronic illness respectively. The main reason for testing was hospitalization among cases which accounts $146(64.9 \%)$. Regarding time gab between testing and starting care, $80(36.2 \%)$ were staring care $>6$ months. Seventy seven (50.7\%), 39(20.4\%) among cases were having symptoms while starting care .Out of the participants, $32(39.0 \%)$ cases were not getting support by health care providers while seeking test and care. The overall quality service was perceived as fair and poor, 24(26.4\%), 23 (41.1\%) among cases respectively. 


\section{Factors associated with presentation to HIV care}

After considering all assumptions of binary logistic regression, those variables with $p$-value $<0.25$ in bivariate analysis were entered into multivariable logistic regression. Marital status, prior HIV related teaching before enrolment to care, symptom while starting care, presence of chronic illness and challenge faced during care, treatment seeking before starting care, time gab in testing and starting care, contact with commercial sex workers ,HIV disclosure statues to partner ,alcohol consumption and stigma were associated with presentation to HIV care during bivariate logistic regression.

In Multivariable logistic regression only prior HIV related teaching before enrolment to care, symptom while starting care, presence of chronic illness and challenge faced during care were found to be independent predictors of late presentation . During bivariate logistic regression variables significant at $p$ value $<0.25$ were entered to multivariable logistic regression analysis. Variables were taken as significantly associated factors of HIV with p-value less than 0.05 .

The odds of late presentation is 3.48 times higher among those who didn't get prior HIV related teaching before enrolment to care as compared to those who got $(A O R=3.48(1.57-7.70)$ and participants who had symptom while starting care were 3.85 more (AOR=3.85(1.91-774) likely to be late as compared to those who had not t symptom while starting care.

The odds of being having history of chronic illness were 4.59 times more than those who didn't history chronic illness (AOR=4.59, 95\% $\mathrm{Cl}: 2.17-9.74)$. Moreover, participants who faced challenge during care were $1.84(\mathrm{AOR}=1.84,95 \% \mathrm{Cl}: 0.13-0.77)$ more likely to be late as compared to those who did not face any challenge during care.

\section{Discussion}

This study reveals that prior HIV related teaching before enrolment to care was significantly associated with late presentation. This is supported by the study conducted in South Wollo. This could be due to similar in accessing information and similar characteristics. But this result is higher than the study conducted in Zimbabwe (11). This diference could be due to diference in provision of information sample size, and accessing service opportunities among participants.

This case control study has identified experiencing symptom while starting care was stastically associated with late presentation to HIV care. This result is inconsistent with the study conducted in Netherland (10). This diference could be due to provisions of HIV related information among individuals and health care access. But lower than the study conducted in Ethiopia, south Wollo (13).The diference might be due to time of study, sample size, study population, study design and information dissemination about advantage of testing.

In contrast, a study conducted in North West Ethiopia (8) indicated that participants who started care with presence of symptoms and illness were positively and stastically associated with late presentation. This 
diference might be due to sample size, updated and accessibility of service through time and awareness among participants.

In this study, presence of chronic illness was significantly associated with late presentation to HIV care. This finding is in line with the study conducted in Ethiopia, Bahirdar (7). This could be similar in characteristics, accessing health service .But this result is lower than the study conducted in Canada (15).This diference could be diference in time of study, study population and sample size.

The current study had identified that challenge faced while accessing during care was significantly associated with late presentation to HIV care .But this result is inconsistent with the study conducted in Ethiopia and Kenya respectively $(4,6)$.These studies shows that individuals who had history of challenges faced were at risk to be late presenters. This could be the diference in time of study, sample size, study population and information about HIV transmission .But, the current study is opposite to the study conducted in California and New Zealand $(14,17)$ respectively. This difference could be due to variation in provision of materials and drugs, alternatives of other opportunities.

This study indicated that sex, marital status, income, alcohol consumption, HIV disclosure status, contact with commercial sex workers and stigma were not associated with HIV presentation .But this result findings is opposite with the studies conducted in Brazil, Zimbabwe, Benin, Kenya, Nigeria $(8,11,12,13$, 17).This might be due to diference in behavioral change among individuals, time of the study, characteristics and quality service provided.

Late HIV presentation can lead to different health problem, even death. Therefore it needs to be considered that Late HIV presentation as part of HIV treatment protocols to prevent further complication.

\section{Conclusion}

This study was found prior HIV related teaching before enrolment to care, symptom while starting care, presence of chronic illness and challenge faced during care.

Assessing factors which puts HIV patients late in enrolling care .Based on the results of the current study, the following recommendations are forwarded:

\section{For patients}

Have a regular follow up for their treatment and take appropriate management as per the heathcare provider .And be cooperative and supportive in minimizing risk factors which exposes HIV patients to be late in enrolling to care.

\section{For health providers}

Helps to give health education and create awareness for patients about testing and counseling and its merits. 


\section{For Ayder comprehensive specialized hospital, Mekelle, Quiha and Hewo hospitals}

It is better to give emphasis in providing prior HIV related teaching and cousling which will enable the professionals to give enough information about impact of enrolling to care late.

To work on solving the challenges faced during care of patients.

\section{For Tigray regional health beauro}

To work on providing health education towards HIV transmitions and prevention mechanisms.

For researchers'

Further studies will be important to identify risk factors which are associated with late presentation to HIVcare.

\section{Limitation of the study}

This study did not include patients attending private health facilities and who did not visit health institutions during the time of the study period.

\section{Declarations}

\section{Ethics approval and consent to participate}

Ethical clearance and approval was obtained from the institutional review board of Mekelle University CHS. Letters of permission was obtained from each hospitals Moreover, prior to conducting the study, the purpose and objective of the study was described to the study participants and verbal informed consent was obtained since most of the participants were illiterate. The study participants were informed as they had full right to discontinue during the interview. Participants' confidentiality and any special data security requirements was maintained and assured by not exposing patients name and information. According the university ethical clearance rule and regulation by the Reference Number of MU/ 1339 /2019.

\section{Consent for publication}

Not applicable as there is no image or other confidentiality related issues.

\section{Availability of data and materials}

The datasets used during the current study is available from the corresponding author on reasonable request.

\section{Competing interests}

The author declares that they have no competing interests. 


\section{Funding}

Mekelle University was the source of funding (refence No.1339 /2019).

\section{Author's contribution}

$\mathrm{DH}, \mathrm{HM}$ and $\mathrm{KB}$ make interpretation of the data and helping during analysis. TA prepares and submits the manuscript.

\section{Acknowledgements}

Authors thanks to Mekelle University and the data collectors, supervisors and study participants.

\section{Author's information}

1. Teklay Araya, Department of Adult health nursing, Ayder Comprehensive specialized Hospital, Mekelle University, Tigray, Ethiopia.

Email: teklayaraya57@gmail.com

Phone no. +251945074968

2. Desta Hailu, Department of RH and maternity, School of nursing, Mekelle University, Tigray, Ethiopia.

Email: destahailu19@gmail.com

Phone no. +251934722071

3. Hiwote Melese, Department of RH and maternity, School of nursing, Mekelle University, Tigray, Ethiopia

Email: to2hiwi@gmail.com

Phone no. +251913164896

4. Kiros Belay, Department of Adult health nursing, School of nursing, Mekelle University, Tigray, Ethiopia.

Email: kirosbelayee@gmail.com

Phone no. +251902539059

\section{References}

1. Beyene MB, Beyene HB. Predictors of Late HIV Diagnosis among Adult People Living with HIV / AIDS Who Undertake an Initial CD 4 T Cell Evaluation, Northern Ethiopia : A Case-Control Study. 2015;1-12.

2. Nyika $H$, Mugurungi $O$, Shambira G, Gombe NT, Bangure D. Factors associated with late presentation for HIV / AIDS care in Harare City , Zimbabwe , 2015. BMC Public Health 2016;8(10):1-7. Available from: http://dx.doi.org/10.1186/s12889-016-3044-7 
3. Agaba PA, Meloni ST, Sule HM, Agbaji OO, Ekeh PN, Job GC, et al. Patients who present late to HIV care and associated risk factors in Nigeria. HIV Assoc Orig. 2014;(December 2013):396-405.

4. Gelaw YA, Senbete GH, Adane AA, Alene KA. Determinants of late presentation to HIV / AIDS care in Southern Tigray Zone, Northern Ethiopia : an institution based case - control study. AIDS Res Ther. 2015;1-8.

5. Gesesew HA, Tesfamichael FA, Adamu BT. Factors Affecting Late Presentation for HIV / AIDS Care in Southwest Ethiopia : A Case Control Study. 2013;3(4):98-107.

6. Kwobah CM, Braitstein P, Koech JK, Simiyu G, Mwangi AW, Wools-kaloustian K, et al. Factors Associated with Late Engagement to HIV Care in Western Kenya : A Cross-Sectional Study. HIV Clin Manag Factors. 2016;15(6):505-11.

7. Aniley AB, Ayele TA, Zeleke EG, Kassa AA. Factors associated with late Human Immunodeficiency Virus ( HIV ) diagnosis among peoples living with it, Northwest Ethiopia : hospital based unmatched casecontrol study. BMC Public Health [Internet]. 2016;1-8.

8. Abaynew Y, Deribew A, Deribe K. Factors associated with late presentation to HIV / AIDS care in South Wollo ZoneEthiopia : a case-control study. AIDS Res Ther [Internet]. 2011;8(1):8.

9. Darcis G, Lambert I, Sauvage A, Frippiat F, Meuris C, Uurlings F, et al. Factors associated with late presentation for HIV care in a single Belgian reference center : 2006 - 2017. Sci Rep. 2018;(March):1-6.

13. Zannou DM, Gandaho PB, Azon-kouanou A, Ahouada C, Agbodande KA, Wanvoegbe A, et al. Late Presentation to Care among People Living with HIV in Cotonou , Benin : A Retrospective Analysis from 2003 to 2014. 2017;123-34.

10. Noble $G^{1}$, Okpo $E^{1,2}$, Tonna I ${ }^{3}$, Fielding $S^{1}$, factors associated with late HIV diagnosis in North-East Iran , a six-year retrospective study, Journal of the International AIDS Society 2015, 18:20317

11. Weibin Cheng, ${ }^{1}$ Weiming Tang, ${ }^{2}$ Zhigang Han, ${ }^{1}$, Late Presentation of HIV Infection: Prevalence, Trends, and the Role of HIV Testing Strategies in Guangzhou, China, 2008-2013, BioMed Research International Volume 2016.

12. Eline L M Op de Coul, Factors associated with presenting late or with advanced HIV disease in the Netherlands, 1996-2014: results from a national observational cohort. BMJ Open 2016.

13. Abebayehu Bitew Aniley, Factors Associated with Late HIV Diagnosis among Peoples Living with HIV, Northwest Ethiopia: Hospital based Unmatched Case-control Study. 2016 . Vol. 2 No. 1:4

14. Sobrino V, Lucia G, Ana M, et al. Delayed diagnosis of HIV infection in a multicenter cohort: prevalence, risk factors, response to HAART and impact on mortality. Curr HIV Res, 2009.7:224-30. 
15. Oliva J, Galindo S, Vives N, et al. Delayed diagnosis of HIV infection in Spain. Enferm Infecc Microbial Clin, 2010. 28:583-89.

16. Madeleine O, Fleur O, et al. Delay between first HIV related symptoms and diagnosis of HIV infection in patients attending the internal medicine department of then foundation Jeanne Ebori (FJE), Libreville, Gabon. HIV Clin Trials, 2005.6(1):38-42

20. Kamalika M, Madhu V, Neeraj C, and Sanjay M. Research article late presenters to HIV care and treatment, identification of associated risk factors in HIV-1 infected Indian population, BMC Public Health, 2010.10:416.

\section{Tables}

Table1: Socio-demographic factors associated with late presentation to HIV care among patients attending in public hospitals of Mekelle city, Tigray, Ethiopia, 2018/2019(n=343). 


\begin{tabular}{|c|c|c|c|}
\hline \multicolumn{2}{|l|}{ Variables } & \multirow{2}{*}{$\begin{array}{l}\text { Case } \\
\text { N (\%) }\end{array}$} & \multirow{3}{*}{$\begin{array}{l}\text { Control } \\
\text { N (\%) }\end{array}$} \\
\hline & & & \\
\hline \multirow{2}{*}{ Sex } & Malo & & \\
\hline & Female & $69(345)$ & $131(655)$ \\
\hline \multirow{4}{*}{ Age } & $18-40$ & $53(29.6)$ & $126(70.4)$ \\
\hline & $41-49$ & $45(39.8)$ & $68(60.2)$ \\
\hline & $50-59$ & $11(34.4)$ & $21(65.6)$ \\
\hline & $=>60$ & $5(26.3)$ & $14(73.7)$ \\
\hline \multirow[t]{3}{*}{ Residence } & Rural & $30(29.1)$ & $73(70.9)$ \\
\hline & urban & $84(35.0)$ & $156(65.0)$ \\
\hline & Single & $18(24.7)$ & $55(75.3)$ \\
\hline \multirow[t]{3}{*}{ Marital status } & Married & $33(30.6)$ & $75(69.4)$ \\
\hline & Divorced & $45(36.9)$ & $77(63.1)$ \\
\hline & Widowed & $18(45.0)$ & $22(55.0)$ \\
\hline \multirow[t]{5}{*}{ Educational status } & $\begin{array}{l}\text { Unable to write and } \\
\text { read }\end{array}$ & 23(31.9) & $49(68.1)$ \\
\hline & Able to write and read & $5(25.0)$ & $15(75.0)$ \\
\hline & Primary school & $48(36.9)$ & $82(63.1)$ \\
\hline & Secondary school & $24(28.2)$ & $61(71.8)$ \\
\hline & College and above & $14(33.2)$ & $22(61.1)$ \\
\hline \multirow[t]{3}{*}{ Occupation } & Government employed & $13(40.6)$ & $19(59.4)$ \\
\hline & Self employed & $77(32.8)$ & $158(67.2)$ \\
\hline & Unemployed & $24(31.6)$ & $52(68.4)$ \\
\hline \multirow[t]{4}{*}{ Monthly income of the participants } & $0-600$ & $14(32.6)$ & $29(67.4)$ \\
\hline & $601-1650$ & $26(35.1)$ & $48(64.9)$ \\
\hline & $1651-3200$ & $45(30.4)$ & 103(69.6) \\
\hline & $>3201$ & $29(37.2)$ & $49(62.8)$ \\
\hline \multirow{3}{*}{$\begin{array}{l}\text { Owner of the house where participants } \\
\text { live }\end{array}$} & Self & $74(37.0)$ & $126(63.0)$ \\
\hline & Family & $11(28.2)$ & $28(71.8)$ \\
\hline & House renters & $29(27.9)$ & $75(72.1)$ \\
\hline \multirow{4}{*}{$\begin{array}{l}\text { Transport fee to the health facility hey } \\
\text { served }\end{array}$} & $<10$ birr & $27(35.1)$ & $50(64.9)$ \\
\hline & 11-30 birr & $39(33.6)$ & $77(66.4)$ \\
\hline & $31-60$ & $30(33.3)$ & $60(66.7)$ \\
\hline & $>61$ & 18(30.0) & $42(70.0)$ \\
\hline
\end{tabular}

Table 2: Socio-cultural factors associated with late presentation to HIV care among patients attending in public hospitals of Mekelle city, Tigray, Ethiopia, 2018/2019(n=343). 


\begin{tabular}{|c|c|c|c|}
\hline \multicolumn{4}{|l|}{ Variables } \\
\hline & & $\begin{array}{l}\text { Case } \\
\text { N (\%) }\end{array}$ & $\begin{array}{l}\text { Control } \\
\text { N (\%) }\end{array}$ \\
\hline \multirow[t]{2}{*}{ HIV disclosure status } & Yes & $30(28.6)$ & $75(71.4)$ \\
\hline & No & $84(35.3)$ & $154(64.7)$ \\
\hline \multirow[t]{3}{*}{ Alcohol consumption } & Never & $25(16.9)$ & $123(83.1)$ \\
\hline & Some times & $36(26.9)$ & $98(73.1)$ \\
\hline & Many times & $53(86.9)$ & $8(13.1)$ \\
\hline \multirow[t]{2}{*}{ Contact with commercial sex workers } & No & $82(31.4)$ & $179(68.6)$ \\
\hline & Yes & $32(39.0)$ & $50(61.0)$ \\
\hline
\end{tabular}

Table 3: Heath system and provider factors associated with late presentation to HIV care among patients attending in public hospitals of Mekelle city, Tigray, Ethiopia, $2018 / 2019(n=343)$.

\begin{tabular}{|c|c|c|c|}
\hline \multicolumn{4}{|l|}{ Variables } \\
\hline & & $\begin{array}{l}\text { Case } \\
\text { N (\%) }\end{array}$ & $\begin{array}{l}\text { Control } \\
\text { N (\%) }\end{array}$ \\
\hline \multirow[t]{2}{*}{ Challenge faced during care } & No & $73(41.2)$ & $104(58.8)$ \\
\hline & Yes & $41(30.5)$ & $125(69.5)$ \\
\hline \multirow[t]{2}{*}{ Prior HIV related teaching before enrolment to care } & Yes & $39(25.5)$ & $114(74.5)$ \\
\hline & No & $75(39.5)$ & 115(60.5) \\
\hline \multirow[t]{2}{*}{ Treatment seeking anywhere before enrolling to care } & Yes & $37(41.6)$ & $52(58.4)$ \\
\hline & No & $77(30.3)$ & $177(69.7)$ \\
\hline
\end{tabular}

Table 4:Perceived Susceptibility and Perceived benefits factors associated with presentation to HIV care among patients attending in public hospitals of Mekelle city, Tigray, Ethiopia, $2018 / 2019(n=343)$ 


\begin{tabular}{|c|c|c|c|}
\hline \multicolumn{4}{|l|}{ Variables } \\
\hline & & $\begin{array}{l}\text { Case } \\
\text { N (\%) } \\
\end{array}$ & $\begin{array}{l}\text { Control } \\
\text { N (\%) }\end{array}$ \\
\hline \multirow[t]{2}{*}{ Perception HIV as stigmatizing disease } & No & $20(35.7)$ & $36(64.3)$ \\
\hline & Yes & $94(32.8)$ & $193(67.2)$ \\
\hline \multirow[t]{2}{*}{ Perceived ART side effect } & No & $79(34.5)$ & $150(65.5)$ \\
\hline & Yes & $35(30.7)$ & $79(69.3)$ \\
\hline \multirow[t]{2}{*}{ Perceived stigma as barrier to HIV testing and care } & No & $26(27.1)$ & $70(72.9)$ \\
\hline & Yes & $88(35.6)$ & $159(64.4)$ \\
\hline \multirow[t]{2}{*}{ Perception towards benefit of early care } & Yes & $96(34.4)$ & 183(65.6) \\
\hline & No & $18(28.1)$ & $46(71.9)$ \\
\hline
\end{tabular}

Table 5: Clinical -factors associated with late presentation to HIV care among patients attending in public hospitals of Mekelle city, Tigray, Ethiopia, 2018/2019(n=343). 


\begin{tabular}{|c|c|c|c|}
\hline \multicolumn{2}{|l|}{ Variables } & \multirow{2}{*}{$\begin{array}{l}\text { Case } \\
\text { N (\%) }\end{array}$} & \multirow{2}{*}{$\begin{array}{l}\text { Control } \\
\text { N (\%) }\end{array}$} \\
\hline & & & \\
\hline \multirow[t]{2}{*}{ Time gab in testing and enrolling to care } & $=<6$ months & $34(27.9)$ & $88(72.1)$ \\
\hline & $>6$ month & $80(36.2)$ & $141(63.8)$ \\
\hline \multirow[t]{2}{*}{ Presence of chronic illness } & No & $61(24.0)$ & 193(76.0) \\
\hline & Yes & $53(59.6)$ & $36(40.4)$ \\
\hline \multirow{2}{*}{ Symptoms during starting care } & No & $39(20.4)$ & $152(79.6)$ \\
\hline & Yes & $75(49.3)$ & $77(50.7)$ \\
\hline \multirow[t]{4}{*}{ Reasons for testing } & Pregnancy & 14(38.9) & $22(61.1)$ \\
\hline & Work related & $5(29.4)$ & $12(70.6)$ \\
\hline & Hospitalization & $79(35.1)$ & $146(64.9)$ \\
\hline & Couple testing & $16(24.6)$ & $49(75.4)$ \\
\hline \multirow[t]{2}{*}{ Feeling of ill at the time of starting care } & No & $28(25.9)$ & $80(74.1)$ \\
\hline & Yes & $86(36.6)$ & $149(63.4)$ \\
\hline \multirow{4}{*}{$\begin{array}{l}\text { No.of HIV testing and counseling before } \\
\text { care }\end{array}$} & Nothing & $92(35.2)$ & $169(64.8)$ \\
\hline & Once per year & $7(38.9)$ & $11(61.1)$ \\
\hline & Twice per year & $5(14.7)$ & $29(85.3)$ \\
\hline & $\begin{array}{l}\geq \text { Three times per } \\
\text { year }\end{array}$ & $10(33.3)$ & $20(66.7)$ \\
\hline \multirow[t]{2}{*}{ Support of health provider during care } & Yes & $82(31.4)$ & $179(68.6)$ \\
\hline & No & $32(39.0)$ & $50(61.0)$ \\
\hline \multirow[t]{2}{*}{ information about HIV before care } & Yes & $51(27.0)$ & 138(73.0) \\
\hline & No & $63(40.9)$ & $91(59.1)$ \\
\hline \multirow{2}{*}{$\begin{array}{l}\text { Recommendation for other to get such } \\
\text { service }\end{array}$} & Yes & $64(31.8)$ & $137(68.2)$ \\
\hline & No & $50(35.2)$ & $92(64.8)$ \\
\hline \multirow[t]{2}{*}{ Member of support group } & Yes & $26(32.9)$ & $53(67.1)$ \\
\hline & No & $88(33.3)$ & $176(66.7)$ \\
\hline \multirow[t]{3}{*}{ Overall quality service } & Good & $67(34.2)$ & $129(65.8)$ \\
\hline & Fair & $24(26.4)$ & $67(73.6)$ \\
\hline & Poor & $23(41.1)$ & $33(58.9)$ \\
\hline
\end{tabular}

Table 6: Bivariate and Multivariable logistic regression for factors associated with late presentation to HIV care among patients attending in public hospitals of Mekelle city, Tigray, Ethiopia, 2018/2019(n=343). 
Variables Late presentation COR(95\%CI)AOR(95\%CI) P-value

Yes (\%) No(\%)

Prior HIV related teaching before enrolment to care

\begin{tabular}{|c|c|c|c|c|}
\hline Yes & $75(39.5)$ & $115(60.5)$ & 1.00 & 1.00 \\
\hline No & $39(25.5)$ & $114(74.5)$ & $\begin{array}{l}1.91(1.20- \\
3.04)^{*}\end{array}$ & $\begin{array}{l}3.48(1.57- \\
7.70) * *\end{array}$ \\
\hline
\end{tabular}

Symptom while starting care

$\begin{array}{llllll}\text { Yes } & 75(49.3) & 77(50.7) & 3.80(2.36- & 3.85(1.91- & .001 \\ & & & 6.10)^{*} & 7.74)^{* *} \\ \text { No } & 39(20.4) & 152(79.6) & 1.00 & 1.00\end{array}$

Presence of chronic illness

$\begin{array}{lllll}\text { Yes } & 53(59.6) & 36(40.4) & 4.66((2.79- & 4.59(2.17-0.001 \\ & & & 7.77)^{*} & 9.735)^{* *}\end{array}$

Challenge faced during care

$\begin{array}{lllll}\text { No } & 73(41.2) & 104(58.8) & 1.00 & 1.00 \\ & & & & \\ \text { Yes } & 41(30.5) & 125(69.5) & 2.14(0.20- & 1.84(0.13- \\ & & & 0.65)^{*} & 0.77)^{*}\end{array}$

Note:*significant association at $\mathrm{P}<0.25, * *$ statistically significant at $\mathrm{P}<0.05 . \mathrm{AOR}=$ adjusted odds ratio, $\mathrm{COR}=$ crude odds ratio, $95 \% \mathrm{CI}=95 \%$ confidence interval, $1.00=$ reference

Figures 


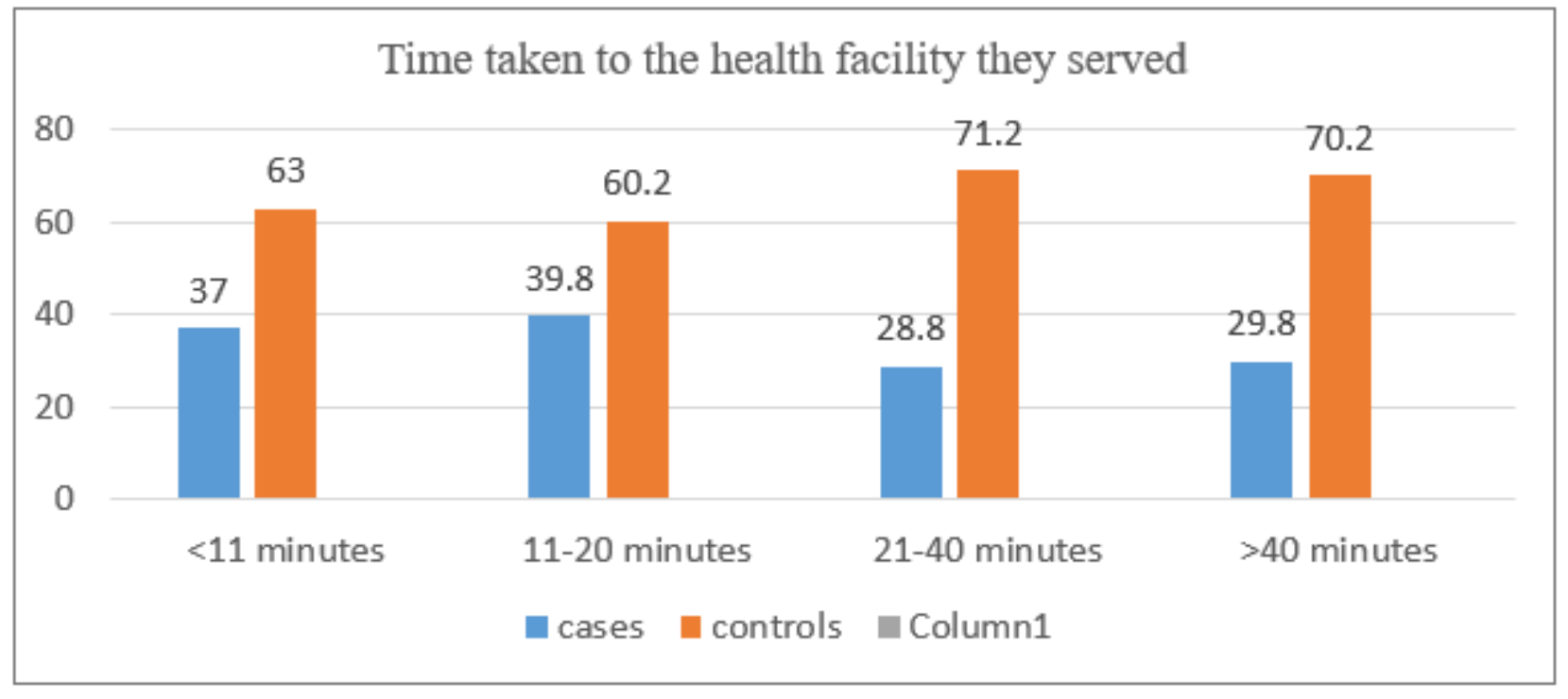

Figure 1

Time taken to the health facility they served 